\title{
Angioarchitectonics and Distribution of Common Carotid Artery Terminals in Domestic Rabbit
}

\author{
Costică Toader COVAȘĂ ${ }^{1 *}$, Alexandru MUNTEANU ${ }^{1}$ \\ ${ }^{1}$ Faculty of Veterinary Medicine, University of Agricultural Sciences and Veterinary Medicine, Iasi, \\ Romania \\ * corresponding author: costica_covasa@yahoo.com
}

Bulletin UASVM Veterinary Medicine 76(1)/2019

Print ISSN 1843-5270; Electronic ISSN 1843-5378

doi:10.15835/buasvmcn-vm: 2018.0026

\begin{abstract}
The purpose of these investigations was to describe the distribution particularities of the common carotid artery in domestic rabbit in correlation with the data in the field. Researches were performed on 6 domestic rabbits, 4 males and 2 female, aged 1-3 years. The common carotid artery was injected with gelatine suspension coloured with Chinese India ink, followed by its dissection. The occipital and internal carotid arteries are detached together in four cases, or separately in the rest of them, from the dorso-medial part of the common carotid artery. Facial and lingual arteries are detached separately, not together, both of which having a large diameter. The superficial temporal trunk which is very developed and long has a sinuous traject between parotid gland acini where it forms two loops. Nearby its origin, the transverse artery of the face has a curved path due to propulsion and retropulsion movements of the temporo-mandibular joint.
\end{abstract}

Keywords: common carotid artery, distribution, rabbit

\section{Introduction}

The structures of the head are supplied by the common carotid artery, a large blood vessel that accompanies the trachea on its lateral sides, being placed into the deepest plan of the jugular groove. At the head basis, behind the curved mandibular branch, it branches into three terminal arteries in most species: external carotid artery, internal carotid artery and occipital artery. Of these, the most bulky and more significant branch is the external carotid artery that spreads through numerous branches to the most head structures. Internal carotid artery and occipital artery supply mainly the encephalus and anterior part of the spinal cord (Coțofan et al., 2000; Spătaru, 2003; Spătaru, 2009).

Many differences concerning the ramification of these blood vessels have been registered, a large variability being observed mainly in the case of the external carotid artery. Also, there were observed some intraspecific variations, too, from an individual to another. From this point of view, the knowledge of the distribution areas of the common carotid artery terminals represents an important goal with many clinical or other applications (Ibrahim et al., Lee et al., 1993; Lee et al., 1994).

In the case of rabbits, researches have noticed a large individual variability regarding the detachment mode of the common carotid artery terminals, being possible the homologation of many morphological subtypes. Jai et al. (1994), after the researches on 105 rabbits, have identified two types depending on the detachment of the internal carotid artery. In first case, its origin is on the lateral side of the common carotid artery, while in the second case, the origin of the internal carotid artery is on the dorso-medial side of the common carotid artery. Also, depending on the occipital artery origin in relation with the internal 
carotid artery, within each type, it was possible to identify three subtypes: A, with the occipital artery origin in the external carotid artery; $\mathrm{B}$, with the origin in the proximal part of the internal carotid artery and C, with the origin in the distal part of the internal carotid artery.

Due to these aspects, additional investigations are required, current researches aiming to describe such particularities in domestic rabbit, in order to complete actual informations from the field.

\section{Materials and methods}

The researches have been carried out on 6 domestic rabbits, adults, both sexes, 4 males and 2 females, aged 1-3 years.

After sacrification, it was identified the common carotid artery and was observed its distribution at the head level. For this purpose, a gelatine suspension coloured with Chinese India ink was injected on the common carotid artery. The gelatine suspension was prepared in advance in a hot water bath, after the obtaining of the suspension being immediately added the Chinese India Ink until the specific coloration was done.

Through dissection were highlighted the detachment mode of the terminals of the common carotid artery and the branches of the external carotid artery. For pictures, it was used the Olimpusx25 Camera.

\section{Results and discussions}

Firstly, it was observed that the common carotid artery emits classically, under the wing of the atlas bone the three terminals, in order of the caliber being represented by external carotid artery, internal carotid artery and occipital artery. Approximately, at the trifurcation site, from the ventral face it detaches the cranial thyroid artery.

On the studied animals, it was found that the origin of the internal carotid artery and occipital artery is on the dorso-medial face of the common carotid artery. In four cases it was registered a common origin and in two cases a separate origin. In first situation, our researches have confirmed the results obtained by the Jai et al. (1994), depending on this, our animals can be framed in the II type, respectively B subtype (Figure 1., Figure 2.).

After a short traject, from the ventral face of the external carotid artery it was noted the separate detachment of the facial and lingual arteries, not in common, both of them having a large caliber. Immediately anterior the external carotid artery emits the superficial temporal trunk, very developed and long at this species. Then, the external carotid artery continues with maxillar artery. Facial artery emits a developed cranial masseteric artery and others masseteric branches (Figure 3. and Figure 4.).

The superficial temporal trunk passes between parotid gland acini and has a sinuous traject with two loops, which follow the neck of the mandible and the base of the ear. At this level, it emits the posterior auricular artery and ends by the transverse artery of the face and cranial auricular artery. On its trajectory, the superficial temporal trunk emits parotidian and muscular branches.

The posterior auricular artery is very developed, being detached from the superficial temporal trunk, at the base of the ear. After a short traject between the tympanic bulla and the base of the ear, it emits the deep auricular artery.

A particularity in rabbits is the sinuous traject of the superficial temporal trunk and also of the transverse artery of the face at the origin. This aspect can be correlated with the propulsion and retropulsion movements of the mandible from the temporo-mandibular joint (Figure 5., Figure 6.).

The transverse artery of the face is well developed and emits many masseteric branches in correlation with the development of the masseter muscle at this species (Spataru et al., 2013).

The maxillary artery has no evident peculiarities. Before the entrance into the alar orifice (Spătaru, 2016), ventrally it emits the alveolomandibular artery, and immediately after the leaving of the alar orifice emits the external ophthalmic artery which has the main branches the phrontal artery and ethmoidal artery. Before the detachment of the inphraorbital artery, the maxillary artery emits the buccal artery (Figure 7.).

\section{Conclusion}

Through researches performed on the arterial vascularization of the rabbit head have been highlighted some particularities of the arterial tree which can contribute to a better knowledge of the circulatory system of this species.

Main points observed have concerned the branching mode of the common carotid artery into the three terminals, the main branches detached from the external carotid artery and the superficial temporal trunk. 


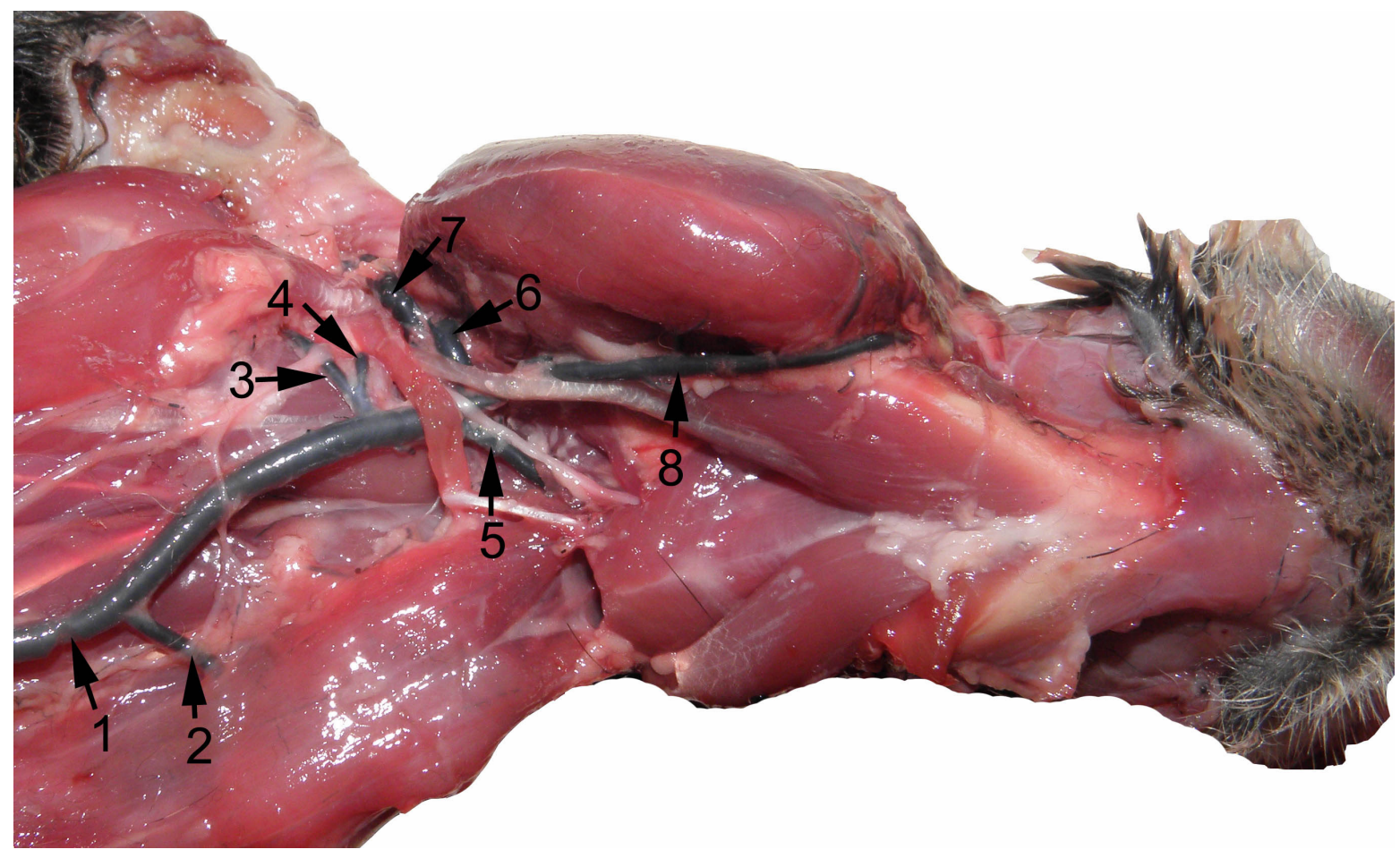

Figure 1. Common origin of the internal carotid artery and occipital artery

1. A. carotis communis; 2. A. thyroidea cranialis; 3. A. occipitalis; 4. A. carotis interna; 5. A. lingualis; 6. A.carotis externa; 7. A. temporalis superficialis; 8. A. facialis.

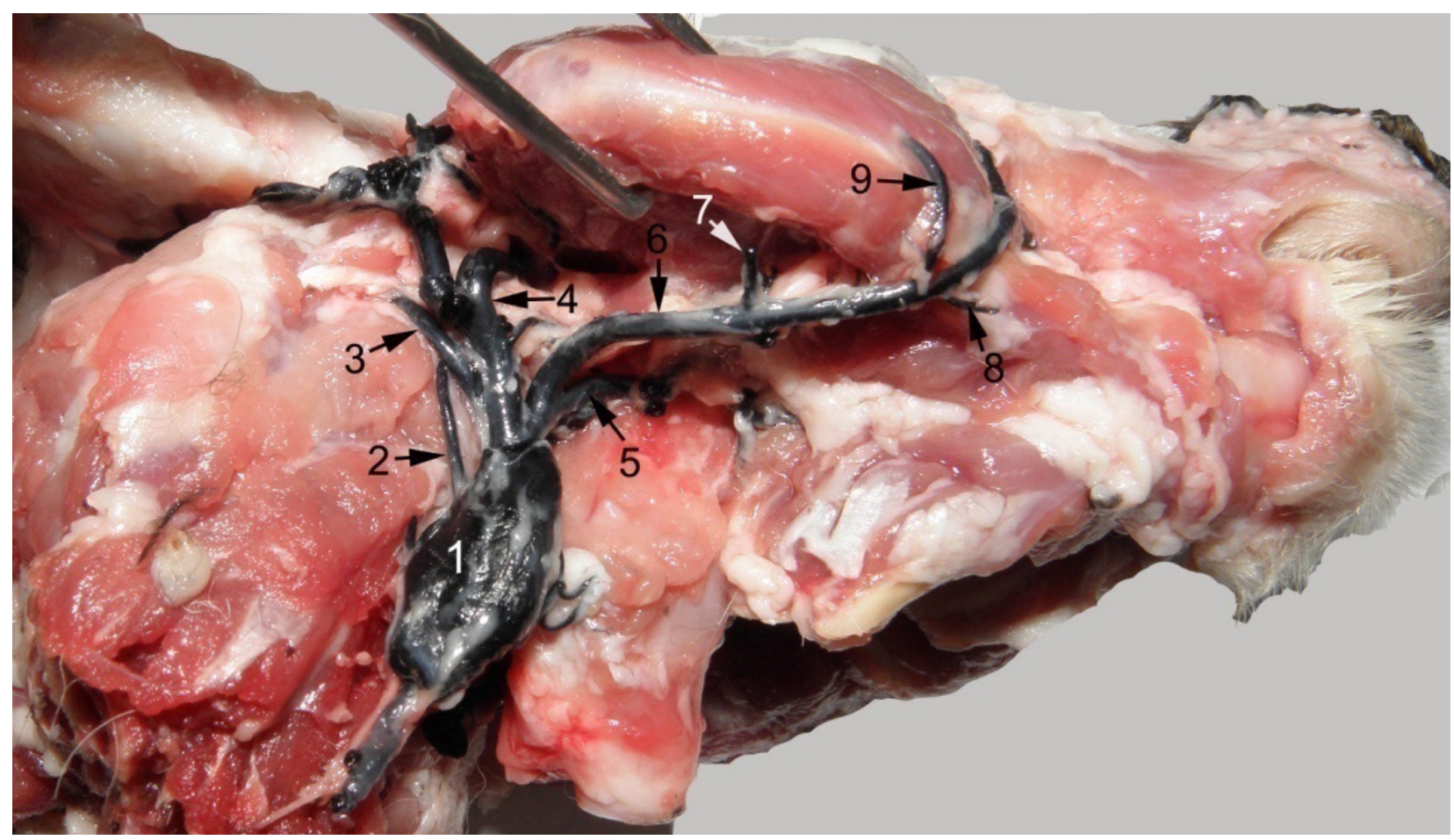

Figure 2. Separate origin of the internal carotid artery and the occipital artery

1. A. carotis communis; 2. A. carotis interna; 3. A. occipitalis; 4. A. carotis externa;

5. A. lingualis; 6. A. facialis; 7. A. sublingualis; 8. A. submentalis; 9. A.maseterica rostralis 


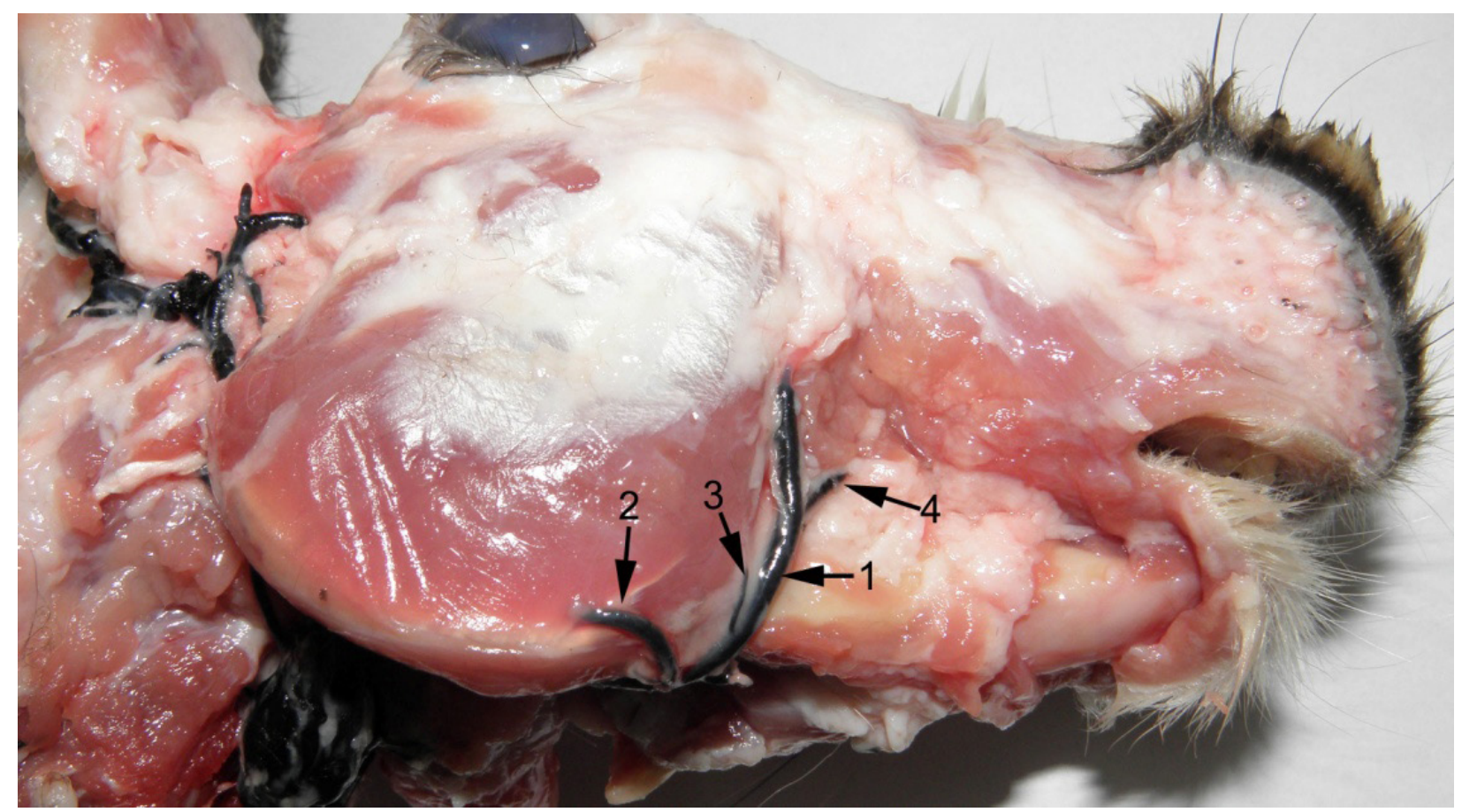

Figure 3. Facial artery

1. A. facialis; 2. A. maseterica rostralis; 3. Ramus massetericus; 4. A. labialis inferior.

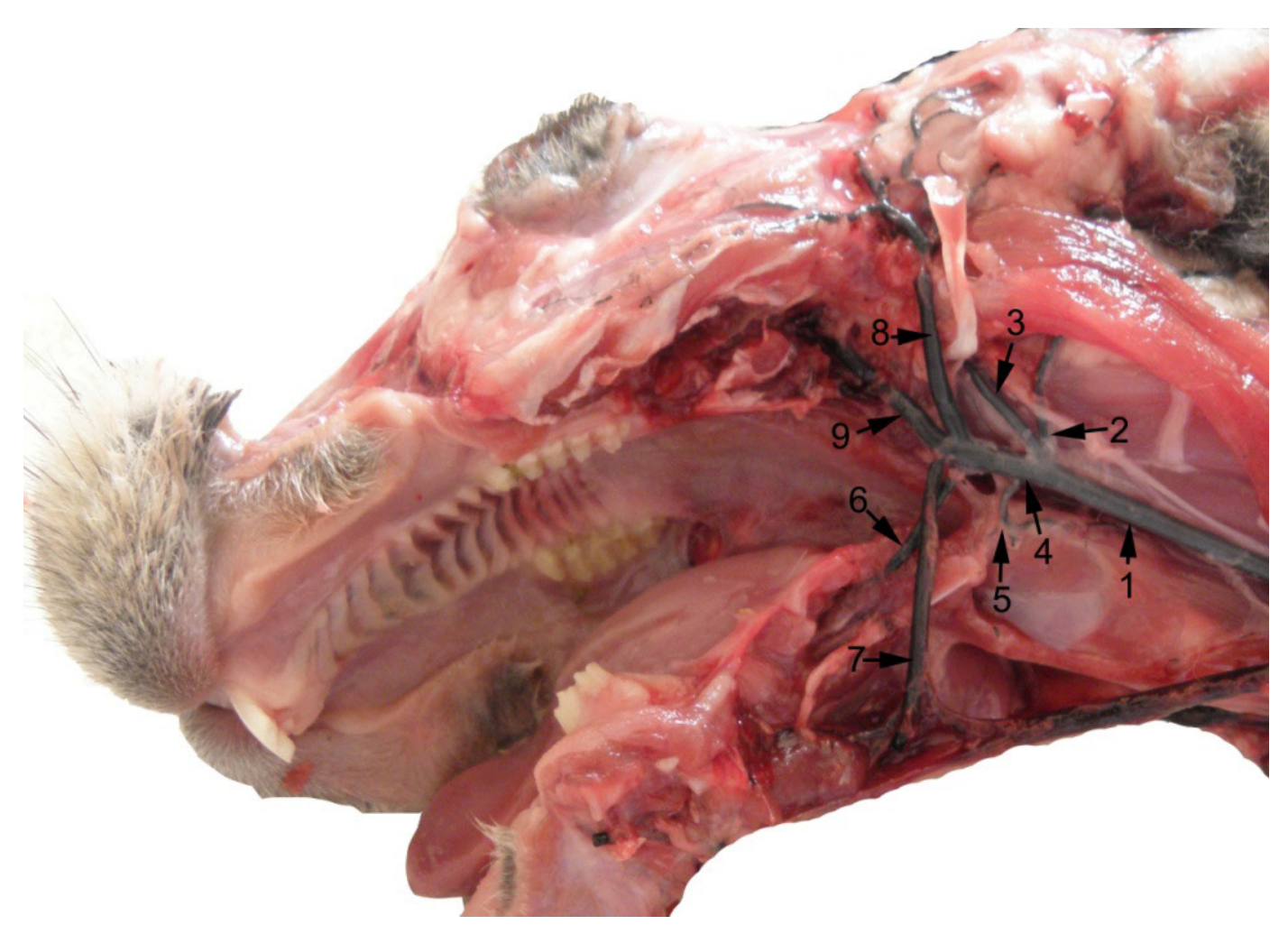

Figure 4. Distribution of the common carotid artery and external carotid artery 1. A. carotis communis; 2. A. occipitalis; 3. A. carotis interna; 4. A. carotis externa; 5. A.thyroidea cranialis; 6. A. lingualis; 7. A. facialis; 8. A. temporalis superficialis; 9. A. maxillaris 


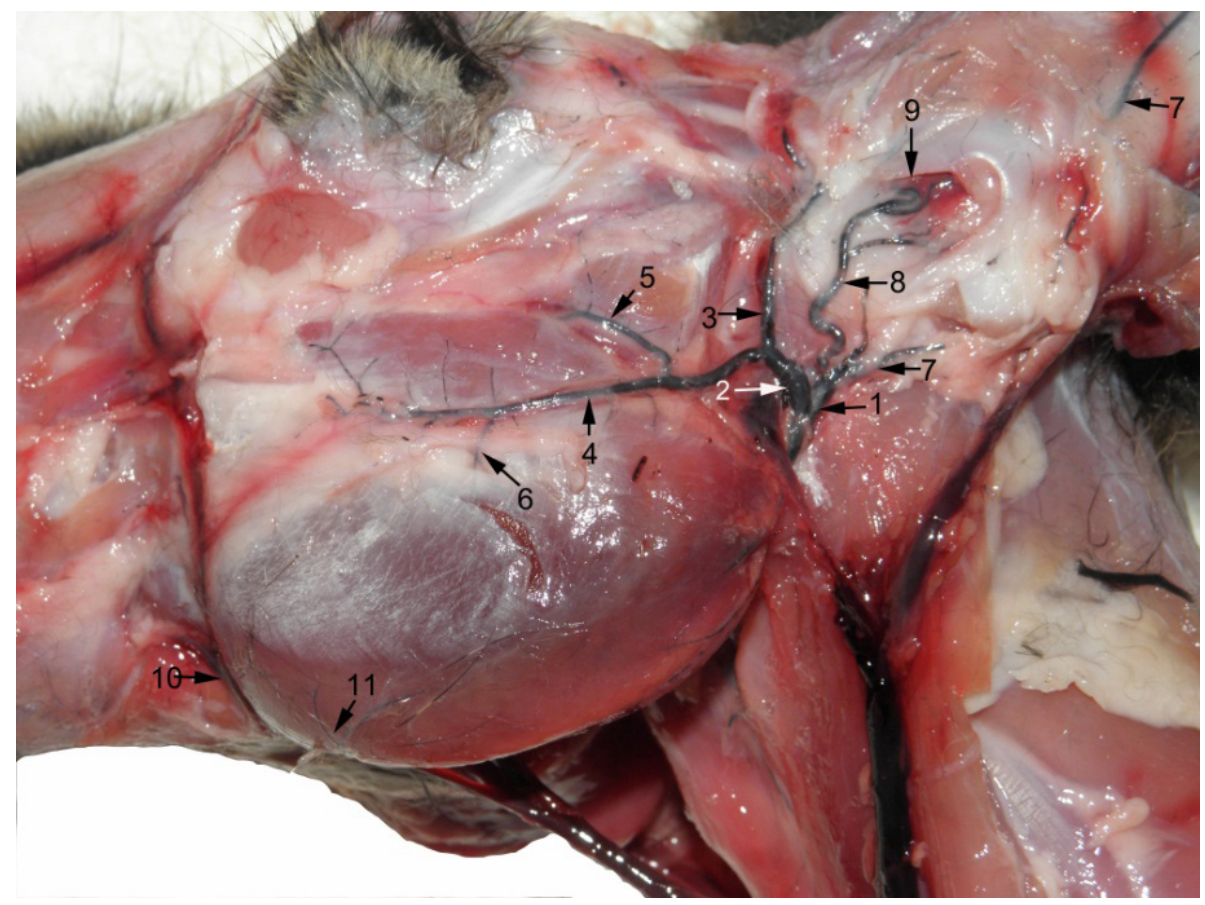

Figure 5. Distribution of the superficial temporal trunk

1. A. auricularis caudalis; 2. A. temporalis superficialis; 3. A. auricularis rostralis; 4. A. transversa faciei; 5-6. Ramus massetericus; 7. Ramus auricularis caudalis; 8. Ramus auricularis intermedius; 9. A. auricularis profunda; 10. A. facialis; 11. A. massetericus rostralis.

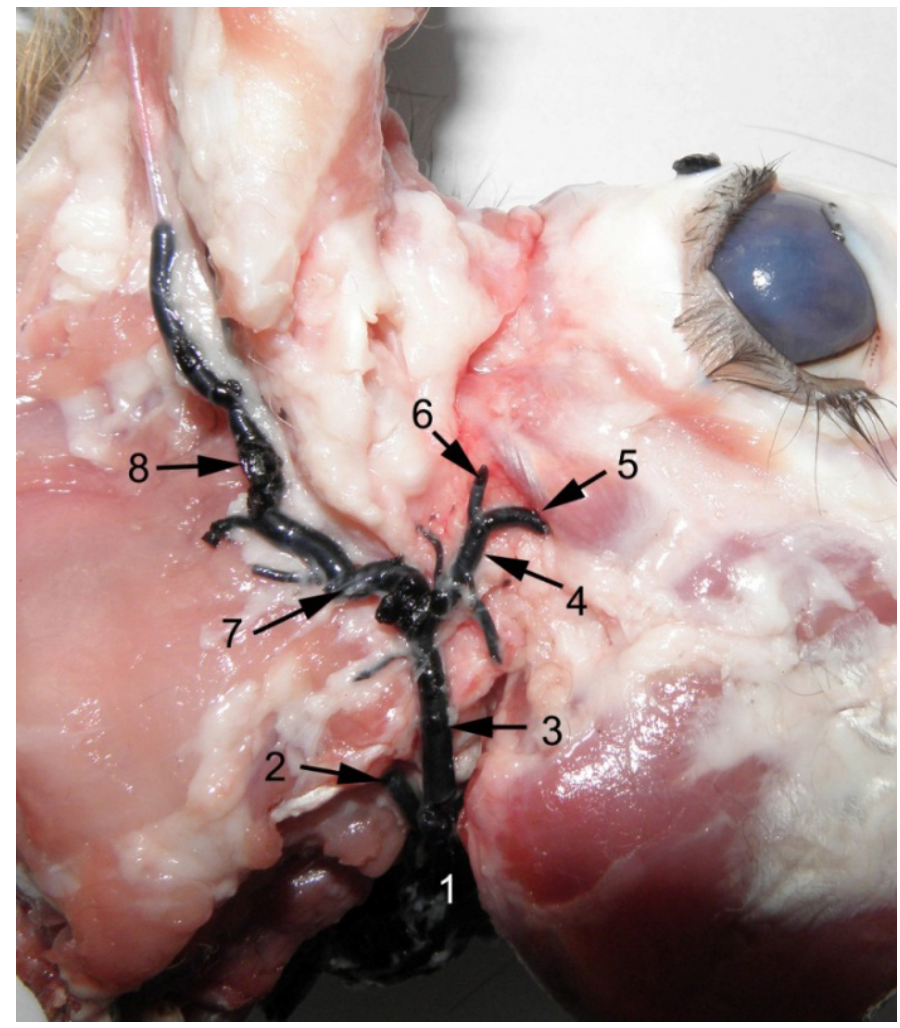

Figure 6. The superficial temporal trunk with his branches: 1. A. carotis communis; 2. A. occipitalis; 3-4. A. temporalis superficialis; 5. A. transversa faciei; 6. A. auricularis rostralis; 7-8. A. auricularis caudalis. 


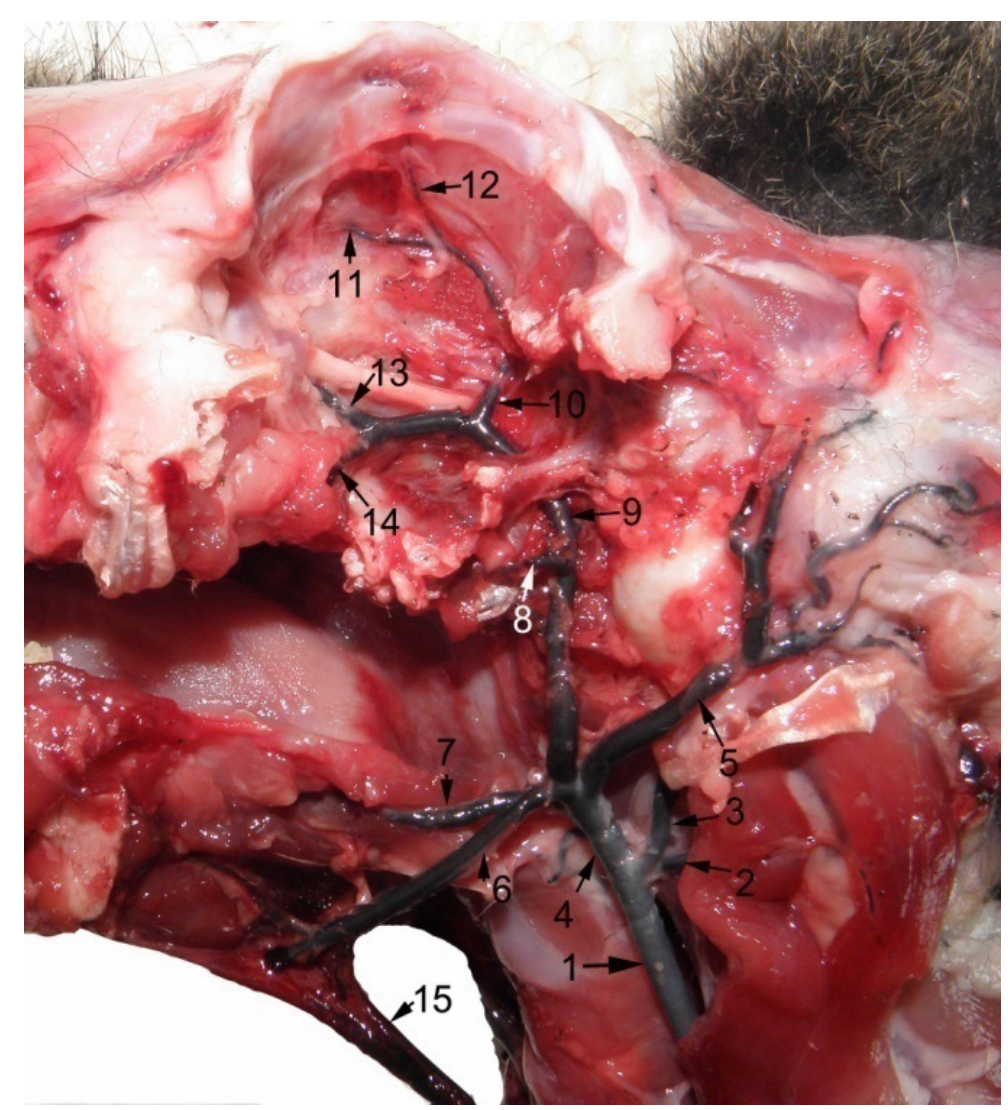

Figure 7. Maxillar artery: 1. A. carotis communis; 2. A. occipitalis; 3. A. carotis interna; 4. A. carotis externa; 5. A. temporalis superficialis; 6. A. facialis; 7. A. lingualis; 8. A. alveolaris inferior; 9. A. maxillaris; 10. A. ophthalmica externa; 11. A. ethmoidalis externa; 12. A. frontalis (supraorbitalis); 13. A. infraorbitalis; 14. A. buccalis.

It was noted the common or separate origin of the internal carotid artery and the occipital artery, the separate origin of the facial and lingual arteries, the development of the superficial temporal trunk, of the posterior auricular artery and the transverse artery of the face with his masseteric branches.

The rabbit represents one of the domestic species with a large degree of intraspecific variability of the head arterial vascularization that determines permanent investigations with experimental and clinical applicability.

Acknowledgments: This research did not receive any specific grant from funding agencies in the public, commercial, or not-for-profit sectors.

\section{References}

1. Coțofan V, Palicica R, Ganță C, Hrițcu V, Enciu V (2000). Anatomy of domestic animals - Circulatory system, Nervous system. Vol. III Timișoara, Ed. Orizonturi universitare (Chapter 1).
2. Ibrahim IA, Abdalla KEH, Abdel-moneim ME, Mansour AA (1990). Arteria carotis externa in the rabbit. Ass. Vet. Med. J., Vol. 23. No.45: 8-18.

3. Lee JS, Hamilton MG, Zabramski JM (1994). Variations in the Anatomy of the Rabbit Cervical Carotid Artery. Stroke, 25: 501- 503.

4. Lee JS, Lee KJ, Sung WH, Choi CR, Spetzler RF (1993). Anatomic Variations in the Bifurcation of Common Carotid Artery in Rabbits. Journal of Korean Neurosurgical Society, 22(3): 400-403.

5. Spataru C (2003). Anatomy of animals - Circulatory system, Nervous system. Iasi, Ed. Alfa (Chapter 1).

6. Spataru C, Spataru M, Vulpe V, Lazar M (2013). The peculiarities of the masticator muscles in rodents. Arquivo Brasileiro de Medicina Veterinária e Zootecnia 65 (3): 749-756.

7. Spataru M (2009). Comparative anatomy of animals. Iasi, Ed Alfa.

8. Spataru M (2016). Comparative morphological peculiarities of the skulls at some rodents (rabbit, nutria, guinea pig and squirrel). University of Agricultural Sciences and Veterinary Medicine, Iasi Scientific papers, Veterinary Medicine 59 (3): 503-509. 